\title{
Isoegomaketone induces apoptosis in SK-MEL-2 human melanoma cells through mitochondrial apoptotic pathway via activating the PI3K/Akt pathway
}

\author{
SOON-JAE KWON ${ }^{1}$, JU-HYE LEE ${ }^{2}$, KWANG-DEOG MOON ${ }^{1}$, IL-YUN JEONG ${ }^{4}$, \\ SUNG-TAE YEE ${ }^{3}$, MI-KYUNG LEE ${ }^{2}$ and KWON-IL SEO ${ }^{2}$ \\ ${ }^{1}$ Department of Food Science and Technology, Kyungpook National University, Daegu 702-701; \\ Departments of ${ }^{2}$ Food and Nutrition and ${ }^{3}$ Biology, Sunchon National University, Suncheon, \\ Jeonnam 540-742; ${ }^{4}$ Advanced Radiation Technology Institute, Korea Atomic Energy \\ Research Institute, Jeongeup, Jeonbuk 580-185, Republic of Korea
}

Received June 13, 2014; Accepted July 24, 2014

DOI: 10.3892/ijo.2014.2598

\begin{abstract}
Isoegomaketone (IK) is a major biologically active component of Perilla frutescens. In this study, we investigated the contribution of reactive oxygen species (ROS) to IK-induced apoptosis in human melanoma SK-MEL-2 cells. We found that IK inhibited the proliferation of SK-MEL-2 human melanoma cells in a dose-dependent manner. IK also induced sub-G1 DNA accumulation, formation of apoptotic bodies, nuclear condensation, and a DNA ladder in SK-MEL-2 cells. IK also induced activation of caspase-3 and -9 , whereas caspase- 8 was unaffected. Further, N-acetyl-L-cysteine (NAC, ROS scavenger) treatment to SK-MEL-2 cells significantly reduced IK-induced cell death. Pretreatment of NAC to SK-MEL-2 cells followed by $100 \mu \mathrm{M}$ IK reduced the protein levels of Bax and cytochrome $c$ as well as PARP cleavage, whereas the protein level of Bcl-2 increased. Moreover, IK inhibited the phosphorylation of AKT/mTOR protein and cell proliferation induced by LY294002, a PI3K inhibitor. In conclusion, IK-induced ROS generation regulates cell growth inhibition and it induces apoptosis through caspase-dependent and -independent pathways via modulation of PI3K/AKT signaling in SK-MEL-2 cells.
\end{abstract}

\section{Introduction}

Oriental medicinal herbs have long been used for the treatment of cancer, but their anticancer mechanisms are not yet fully understood (1). Perilla frutescens (L.) is consumed as a

Correspondence to: Professor Kwon-Il Seo, Department of Food and Nutrition, Sunchon National University, 315 Maegok, Suncheon, Jeonnam 540-742, Republic of Korea

E-mail: seoki@sunchon.ac.kr

Key words: isoegomaketone, apoptosis, reactive oxygen species, apoptosis-inducing factor, SK-MEL-2 human melanoma cell food in East Asia, and it is also used as a medicinal herb (2). Studies on perilla leaf have been carried out to characterize volatile flavor components (3-5). It has been shown that there are three main aromatic active compounds in the volatile component of Perilla frutescens (L.): Perilla ketone (PK), 1-(3-furyl)-4-methyl-3-penten-1-one (egoma ketone, EK), and 1-(3-furyl)-4-methyl-2-penten-1-one (isoegoma ketone, IK) (2). One of these compounds, isoegomaketone (IK) is a major volatile component and is known to possess anti-inflammatory effect (6), inhibiting carcinogenesis of colon cancer (7). However, there have been only a few studies investigating the anticancer mechanisms of IK.

Reactive oxygen species (ROS) are chemically reactive molecules, which are a natural byproduct of normal oxygen metabolism, that play important roles in cell signaling and homeostasis (8). Many studies have reported that during times of environmental stress (e.g., UV or heat exposure), ROS levels can increase dramatically and become a factor in the onset of several major diseases $(9,10)$. However, according to a recent study, ROS generation can be exploited for therapeutic benefits such as suppression of cancer cell growth and induction of apoptosis in cancer cells through regulatory mechanisms (11-13).

The PI3K/AKT/mTOR pathway is an intercellular pathway that plays an important role in apoptosis induction in various cancer cell lines (14-16). Specifically, overexpression of PI3K/AKT protein promotes cancer cell growth and inhibits apoptosis (17). The pathway is regarded an attractive target for anticancer therapy since it is more frequently activated in various tumors than any other signaling pathway $(18,19)$. Recently, there have been many reports showing that ROS generation induces apoptosis in cancer cells through regulation of the PI3K/AKT/mTOR pathway $(20,21)$.

Previous studies have shown that medicinal plants and their components generate ROS, which can activate apoptosis signaling in cancer cells $(22,23)$. Therefore, this study aimed to investigate the cytotoxicity of IK and its potential apoptotic mechanisms through ROS generation and modulation of PI3K/ AKT/mTOR signaling. 


\section{Materials and methods}

Isolation of isoegomaketone. Isoegomaketone (IK) was prepared from Perilla flutescens (L.) Britt. cv. Chookyoupjaso, as described previously (24). In brief, the above-ground portion of Perilla flutescens (L.) Britt. cv. Chookyoupjaso was extracted with $\mathrm{MeOH}$ at room temperature over 3 days. After filtration, $\mathrm{MeOH}$ extract was evaporated and partitioned using ethyl acetate, butanol, and water. The soluble ethyl acetate fraction was separated by column chromatography on silica gel using a gradient of hexane-ethyl acetate. The obtained fraction was further separated to yield IK. The purity and concentration of the isolated IK were confirmed by spectroscopic analysis, and the final IK solution was prepared in sterilized DMSO.

Cell culture. SK-MEL-2 human melanoma cell lines were purchased from the American Type Culture Collection (ATCC, Rockville, MD, USA). Cells were then cultured in RPMI-1640 medium (DMEM, Gibco ${ }^{\circledR} /$ Invitrogen $^{\mathrm{TM}}$, Grand Island, NY, USA) supplemented with $10 \%$ fetal bovine serum (FBS, Gibco/Invitrogen), penicillin (100 IU/ml), and streptomycin $(100 \mu \mathrm{g} / \mathrm{ml})$ in a humidified atmosphere with a $5 \% \mathrm{CO}_{2}$ incubator at $37^{\circ} \mathrm{C}$.

Sulforhodamine B (SRB) assay. Cell viability was determined according to the method of Skehan et al (25). Briefly, IK was added at a range of $0-100 \mu \mathrm{M}$ concentrations for $24 \mathrm{~h}$. Cells were fixed with $50 \%$ trichloroacetic acid to terminate the reaction, after which $0.4 \%$ SRB in $1 \%$ acetic acid was added to each well. After $1 \mathrm{~h}$ of incubation, the plates were washed, and dyes were dissolved with $10 \mathrm{mM}$ Tris buffer. Then, the 96-well plate was read using a micro-plate reader $(540 \mathrm{~nm})$ to obtain the absorbance density values.

sub-G1 DNA content. Cells were seeded at a density of $1 \times 10^{6}$ cells/well in 6-well plates and cultured for $24 \mathrm{~h}$. After culturing, the cells were treated with the indicated concentrations of IK for $24 \mathrm{~h}$. Then, the cells were harvested, washed with cold PBS, and processed for cell cycle analysis as described earlier (26). Briefly, cells were collected and fixed in ice-cold $70 \%$ ethanol in media and stored at $4{ }^{\circ} \mathrm{C}$ overnight. After resuspension, the cells were washed and incubated with $1 \mu 1$ of RNase $(1 \mathrm{mg} / \mathrm{ml})$ (Sigma-Aldrich, St. Louis, MO, USA), $20 \mu \mathrm{l}$ of propidium iodide $(1 \mathrm{mg} / \mathrm{ml}$ ) (Sigma-Aldrich), and $500 \mathrm{ml}$ of PBS at $37^{\circ} \mathrm{C}$ for $30 \mathrm{~min}$. After staining, flow cytometry was performed to analyze sub-G1 DNA content.

Morphological apoptosis. Characteristic apoptotic morphological changes were assessed by fluorescent microscopy using bis-benzimide (Hoechst 33258, Sigma-Aldrich) staining (27). Cells were seeded at a density of $5 \times 10^{5}$ cells/well in 6 -well plates and treated with IK for $24 \mathrm{~h}$. After harvesting, the cells were washed twice with PBS and then stained with $200 \mu 1$ of bis-benzimide $(1 \mu \mathrm{g} / \mathrm{ml})$ for $10 \mathrm{~min}$ at room temperature. Then, $10 \mu \mathrm{l}$ of this suspension was placed onto a glass slide and covered with a cover slip. Cells were then examined with a fluorescence microscope (Olympus Optical Co. Ltd., Tokyo, Japan) to determine nuclei fragmentation and chromatin condensation.
DNA fragmentation. The cells were seeded at a density of $2 \times 10^{6}$ cells in a $100-\mathrm{mm}$ dish, and cultured for $24 \mathrm{~h}$. After culturing, the cells were treated with the indicated concentrations of IK for $24 \mathrm{~h}$, and then collected by centrifugation. The pellets were lysed by DNA lysis buffer $(10 \mathrm{mM}$ Tris- $\mathrm{HCl}$, pH 7.5, 10 mM EDTA, pH 8.0, 0.5\% Triton X-100, 20\% SDS, $10 \mathrm{mg} / \mathrm{ml}$ proteinase $\mathrm{K}$ ) and then centrifuged. The supernatant was fixed in ice-cold $70 \%$ ethanol and stored at $4^{\circ} \mathrm{C}$ overnight. After extraction with phenol buffer (phenol-chloroform and phenol-chloroform-isoamylalcohol) the pellets were incubated with TE buffer (10 mM Tris-HCl, pH 7.4, $1 \mathrm{mM}$ EDTA, $\mathrm{pH} 8.0)$ and RNase $(2 \mathrm{mg} / \mathrm{ml})$ for $1 \mathrm{~h}$ at $37^{\circ} \mathrm{C}$. Then, separation by electrophoresis was performed on $2 \%$ agarose containing ethidium bromide. The DNA bands were examined using a UV Transilluminator Imaging System (28).

Caspase activity. This assay was based on the ability of active enzyme to cleave the chromophore from the enzyme substrate: Ac-DEVD-pNA (for caspase-3), Ac-IETD-pNA (for caspase-8), and Ac-LEHD-pNA (for caspase-9). The cells were seeded at a density of $2 \times 10^{6}$ cells in a $100-\mathrm{mm}$ dish and cultured for $24 \mathrm{~h}$. After culturing, the cells were treated with the indicated concentrations of IK for $24 \mathrm{~h}$ and then collected by centrifugation. The cells were incubated with the peptide substrate in lysis buffer for $30 \mathrm{~min}$ on ice, followed by centrifugation at $10,000 \mathrm{xg}$ for $5 \mathrm{~min}$ at $4^{\circ} \mathrm{C}$. The protein content of the supernatant was measured using BCA protein assay reagent before measuring the activities of caspases-3, -8 and -9 . The supernatant containing $50 \mu \mathrm{g}$ of protein was mixed with DTT in $2 \mathrm{X}$ reaction buffer and the different substrates at $10 \mu \mathrm{M}$. After incubation, the release of $p$-nitroaniline was monitored at $405 \mathrm{~nm}$ (29).

Caspase inhibitor activity. The cells were seeded at a density of $5 \times 10^{5}$ cells/well, and then cultured for $24 \mathrm{~h}$. The cells were preincubated with pan-caspase inhibitor z-VAD-fmk for $2 \mathrm{~h}$, followed by treated with the indicated concentrations of IK for $24 \mathrm{~h}$. For the growth inhibition analysis and measurement of SRB assay, the cells were fixed with 50\% trichloroacetic acid to terminate the reaction, after which $0.4 \% \mathrm{SRB}$ in $1 \%$ acetic acid was added to each well. After $1 \mathrm{~h}$ of incubation, the plates were washed, and dyes were dissolved with $10 \mathrm{mM}$ Tris buffer. Then, the 96-well plate was read using a micro-plate reader $(540 \mathrm{~nm})$ to obtain the absorbance density values.

Measurement of reactive oxygen species. Production of intracellular reactive oxygen species (ROS) was detected by flow cytometry using dichloro-fluorescein diacetate (DCFH-DA) (30). Briefly, B16 cells plated at a density $5 \times 10^{5}$ cells/well were allowed to attach overnight and then exposed to IK for $30 \mathrm{~min}$. Then, the wells were stained with DCFH-DA $(10 \mu \mathrm{M})$ for $30 \mathrm{~min}$ at $37^{\circ} \mathrm{C}$, after which the fluorescence intensity in the cells was determined using flow cytometry.

Western blot analysis. Western blot analyses were performed as described previously (31). Cells were seeded at a density of $2 \times 10^{6}$ cells in a $100-\mathrm{mm}$ dish and cultured for $24 \mathrm{~h}$ in RPMI-1640. After culturing, the cells were treated with the indicated concentrations of IK for $24 \mathrm{~h}$, followed by centrifugation. The resulting pellets were lysed in lysis buffer $(50 \mathrm{mM}$ 


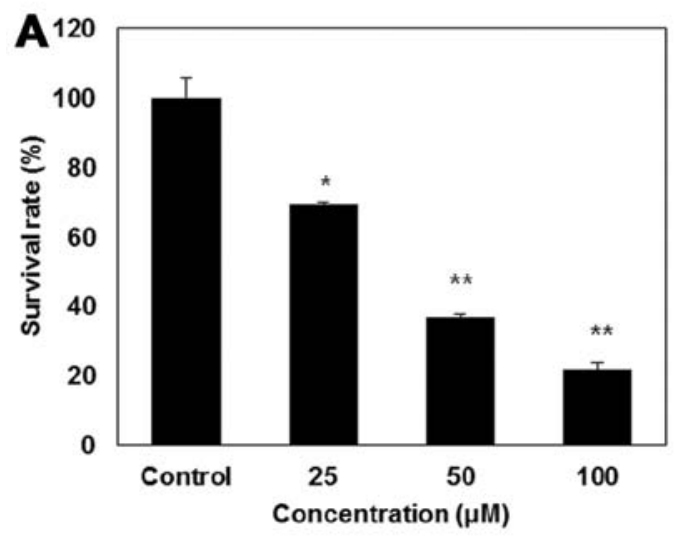

B
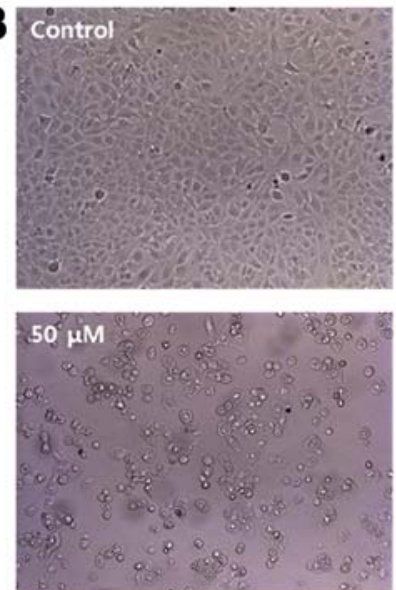

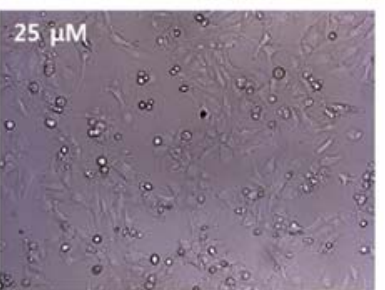

$100 \mu \mathrm{M}$

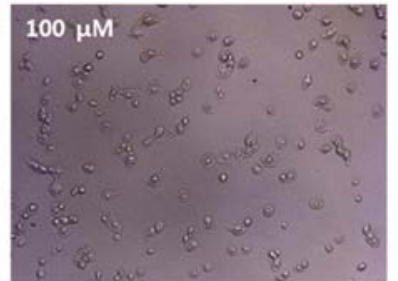

Figure 1. Cell growth inhibitory effects in SK-MEL-2 cells treated with IK for 24 h. (A) Cell viability was measured by SRB assay. Significant differences were compared with the control at ${ }^{*} \mathrm{P}<0.05$ and ${ }^{* *} \mathrm{P}<0.01$ using Student's t-test. (B) After 24-h incubation with IK, cell morphology was visualized by inverted microscopy (x200).

Tris- $\mathrm{HCl}, 150 \mathrm{mM} \mathrm{NaCl}, 1 \mathrm{mM}$ EDTA, $50 \mathrm{mM} \mathrm{NaF}, 30 \mathrm{mM}$ $\mathrm{Na}_{4} \mathrm{P}_{2} \mathrm{O}_{7}, 1 \mathrm{mM}$ PMSF, $2 \mu \mathrm{g} / \mathrm{ml}$ of aprotinin) for $30 \mathrm{~min}$ on ice. To examine the subcellular locations of cytochrome $c$ and AIF (apoptosis-inducing factor), cytosolic extracts were prepared according to the manual provided in the mitochondria isolation kit (Pierce, Rockford, IL, USA). The protein content of the supernatant was measured using a BCA protein assay kit. Briefly, the protein samples were loaded at $10 \mu \mathrm{g}$ of protein/lane and separated by $12 \%$ SDS-PAGE at $100 \mathrm{~V}$ of constant voltage/slab for $1.5 \mathrm{~h}$. Following electrophoresis, the proteins were transferred onto nitrocellulose membranes and blocked with 2.5 and $5 \%$ bovine serum albumin (BSA) for $1 \mathrm{~h}$ at $37^{\circ} \mathrm{C}$. The membranes were then incubated with primary antibody at $4^{\circ} \mathrm{C}$ overnight. Primary antibodies used were anti-Bax (Santa Cruz sc-493), anti-Bcl 2 (Santa Cruz sc-492), anti-PARP (Santa Cruz sc-7150), anti-cytochrome $c$ (Santa Cruz sc-7159), anti-AIF (Santa Cruz sc-5586) and anti- $\beta$ actin (Santa Cruz sc-47778). All primary antibodies presented were used at a 1:1,000 dilution. Finally, the membranes were treated with horseradish peroxidase-coupled secondary antibodies for $1 \mathrm{~h}$ at $4^{\circ} \mathrm{C}$. Secondary antibodies used were goat anti-rabbit IgG (Millipore AP132P) and goat anti-IgG (Millipore AP124P). All secondary antibodies presented were used at a 1:10,000 dilution. The membranes were washed with T-TBS after each antibody binding reaction, and detection of each protein was performed using an ECL reagents kit (Santa Cruz, Dallas, TX, USA).

Statistical analysis. Data were analyzed by Student's t-test to evaluate significant differences. A level of $\mathrm{p}<0.05$ and $\mathrm{p}<0.01$ were regarded as statistically significant.

\section{Results}

Isoegomaketone inhibits cell growth in SK-MEL-2 cells. To investigate whether or not isoegomaketone (IK) inhibits the proliferation of SK-MEL-2 human melanoma cells, cell growth was measured by SRB assay along with morphological characteristics in response to various doses $(0-100 \mu \mathrm{M})$ of IK treated for $24 \mathrm{~h}$ (Fig. 1). As shown in Fig. 1A, treatment with IK reduced cell viability in a dose-dependent manner, and cell viability significantly decreased at $100 \mu \mathrm{M}$ IK. Fig. 1B shows that IK treatment caused a reduction in cell number, cell shrinkage, rounding, and partial detachment in SK-MEL-2 cells. This result indicates that IK induced dose-dependent growth inhibition in SK-MEL-2 cells.

Isoegomaketone induces apoptosis. To assess whether or not cell death induced by IK is related to apoptosis, flow cytometric analysis, Hoechst 33258 staining, and DNA fragmentation assay were performed in melanoma cells treated with IK. After IK treatment for $24 \mathrm{~h}$, the sub-G1 cell population increased in a dose-dependent manner (Fig. 2A) and morphological changes such as nucleus shrinkage, chromatin condensation, and formation of apoptotic bodies was showed at a concentration of 50-100 $\mu \mathrm{M}$ (Fig. 2B). Next, we investigated distinct features of apoptosis, including the DNA fragmentation pattern, using agarose gel electrophoresis. The DNA ladder pattern in IK-treated cells indicated typical internucleosomal fragmentation, especially at IK concentrations of 50-100 $\mu \mathrm{M}$ (Fig. 2C).

Isoegomaketone inducesapoptosis throughcaspase-dependent pathway. A previous study determined that caspase signaling is an important factor of apoptosis (32). To determine whether or not apoptosis induced by IK occurs via a caspase-dependent pathway, z-VAD-fmk, a universal caspase inhibitor, was added along with IK. Fig. 3A shows that although z-VAD-fmk attenuated apoptosis induced by IK, cell death induced via IK was significantly elevated in a dose-dependent manner. In order to confirm the caspases involved in IK-induced apoptosis, caspase activities were measured using a caspase detection kit (colormetric). As shown in Fig. 3, IK activated caspase-3 and -9 in a dose-dependent manner, whereas caspase- 8 was not activated (Fig. 3B). Furthermore, treatment of SK-MEL-2 cells with IK resulted in a dose-dependent increase in PARP cleavage along with upregulation of Bax and downregulation of Bcl-2 (Fig. 3C). 

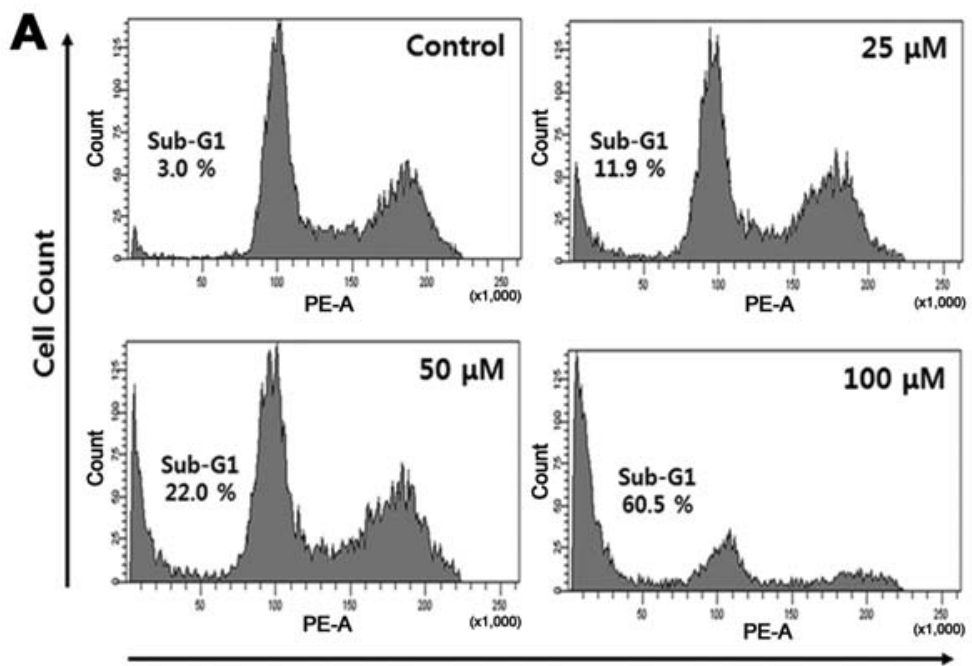

PI

C M Cont. $\frac{\text { IK }(\mu \mathrm{M})}{25 \quad 50 \quad 100}$
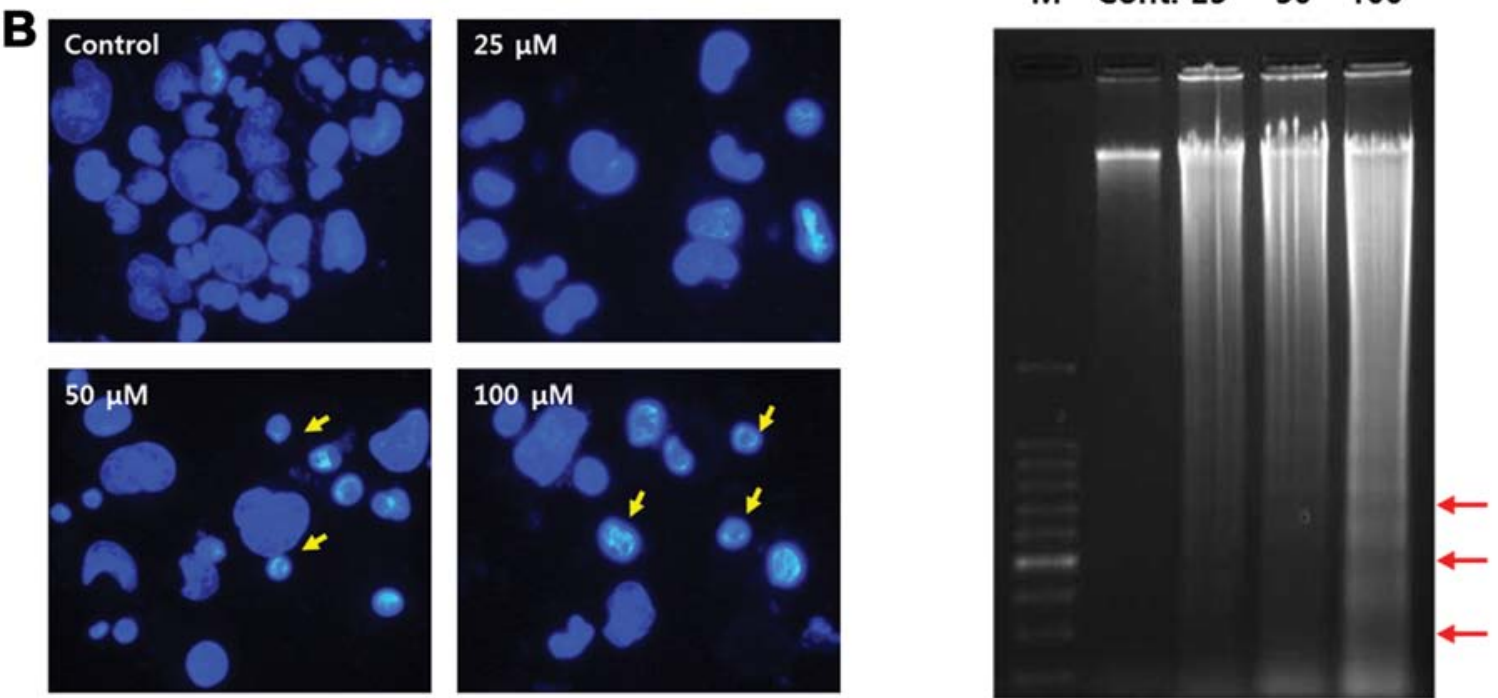

Figure 2. Induction of apoptotic cell death in SK-MEL-2 cells by IK. Cells were treated with or without IK for 24 h. (A) Sub-G1 cell population was analyzed by flow cytometry. (B) Nuclear fragmentation was observed by Hoechst staining. (C) DNA fragmentation was observed by $2 \%$ agarose gel electrophoresis.

Isoegomaketone induces apoptosis through ROS generation in $S K-M E L-2$ cells. ROS generation was measured based on DCF fluorescence to determine whether or not IK increases the level of ROS in SK-MEL-2 cells. Fig. 4A shows that IK-mediated ROS generation was significantly elevated at an IK concentration of $100 \mu \mathrm{M}$. However, cells treated with $100 \mu \mathrm{M}$ IK and $5 \mathrm{mM}$ N-acetyl cysteine (ROS scavenger, NAC) showed a reduced ROS level compared to that of IK-treated cells. We further investigated whether or not elevation of ROS production is involved in IK-induced cell death. This result shows that NAC treatment inhibited IK-induced cell death in SK-MEL-2 cells (Fig. 4B). Furthermore, NAC treatment considerably reduced apoptotic morphological changes (Fig. 4C). These results suggest that ROS were significantly involved in IK-induced apoptosis.

Isoegomaketone-induced ROS generationleads to activation of caspase-dependent and-independent apoptosis in SK-MEL-2 cells. Specific apoptotic parameters, including expression of PARP, Bax, Bcl-2, cytochrome $c$, and AIF, were investigated to determine whether or not IK-mediated ROS production is involved in apoptosis induction in SK-MEL-2 cells (Fig. 5). SK-MEL-2 cells treated with NAC showed strong inhibition of IK-induced PARP cleavage, upregulation of Bax expression, and downregulation of $\mathrm{Bcl}-2$ expression. These results suggest that IK-induced apoptosis in SK-MEL-2 cells was induced by ROS generation in association with a caspase-dependent pathway. Bcl-2 family proteins and cytochrome $c$ commonly stimulate activation of caspases-8, -9 and -3 (33), and AIF involved in initiating a caspase-independent pathway of apoptosis (34). IK-treated cells released cytochrome $c$ and AIF in mitochondria, resulting in higher levels of cytochrome $c$ and AIF in the cytosol. On the other hand, NAC treatment significantly reduced IK-induced release of cytochrome $c$ from mitochondria into the cytosol. These results suggest that IK-induced apoptotic cell death was involved in ROS 

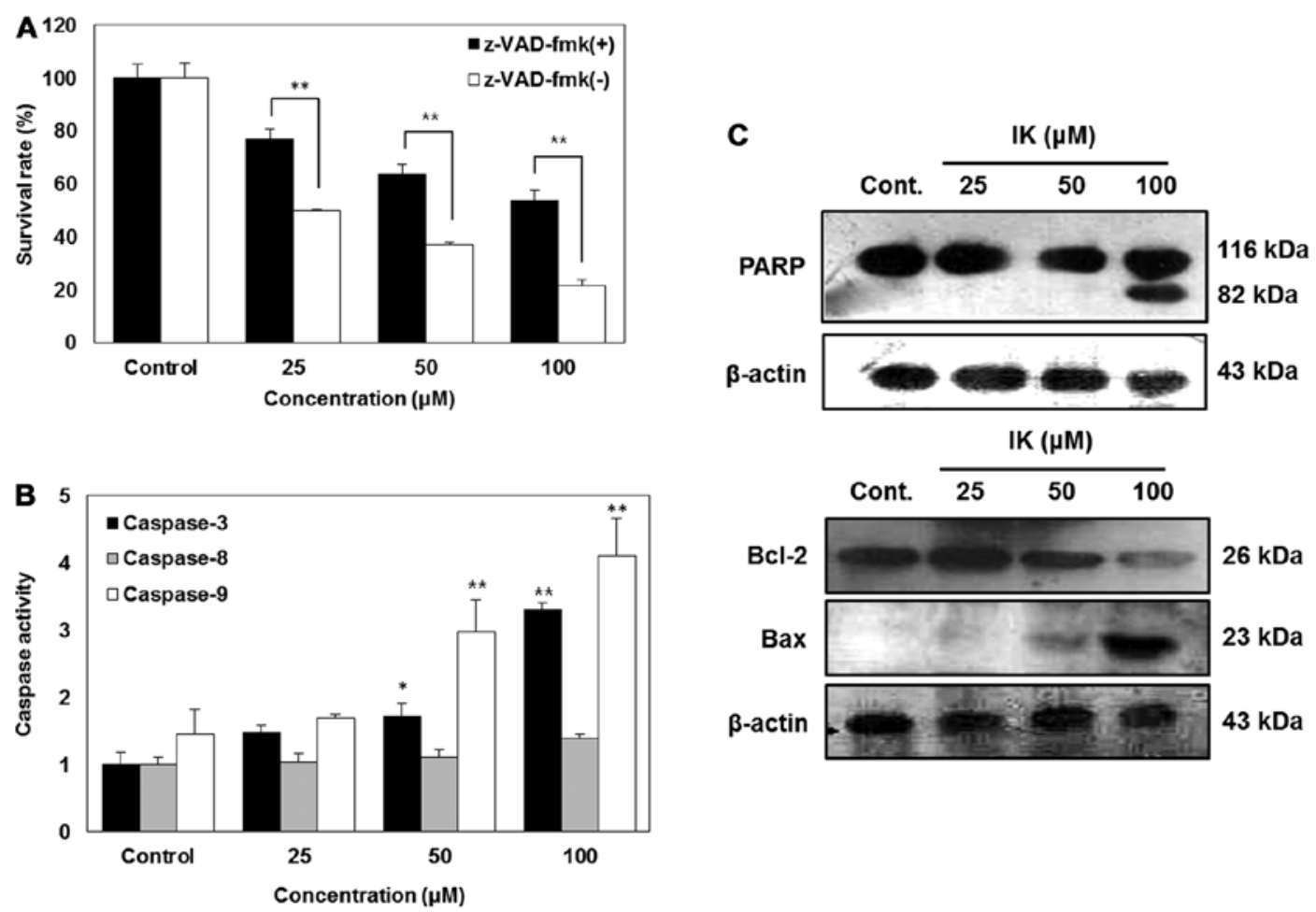

Figure 3. IK induces caspase-independent cell death in SK-MEL-2 cells. (A) Effect of caspase inhibitor on SK-MEL-2 cells treated with IK. SK-MEL-2 cells were pretreated with $10 \mu \mathrm{M}$ z-VAD-fmk for $2 \mathrm{~h}$ prior to IK treatment for $24 \mathrm{~h}$. Cell viability was measured by SRB assay. (B) Activation of caspase- 8 , -9 and -3 in cells treated with IK for $24 \mathrm{~h}$, as detected by a caspase detection colorimetric kit. (C) PARP cleavage as well as Bax and Bcl-2 expression in cells treated with IK for $24 \mathrm{~h}$, as detected by western blotting.
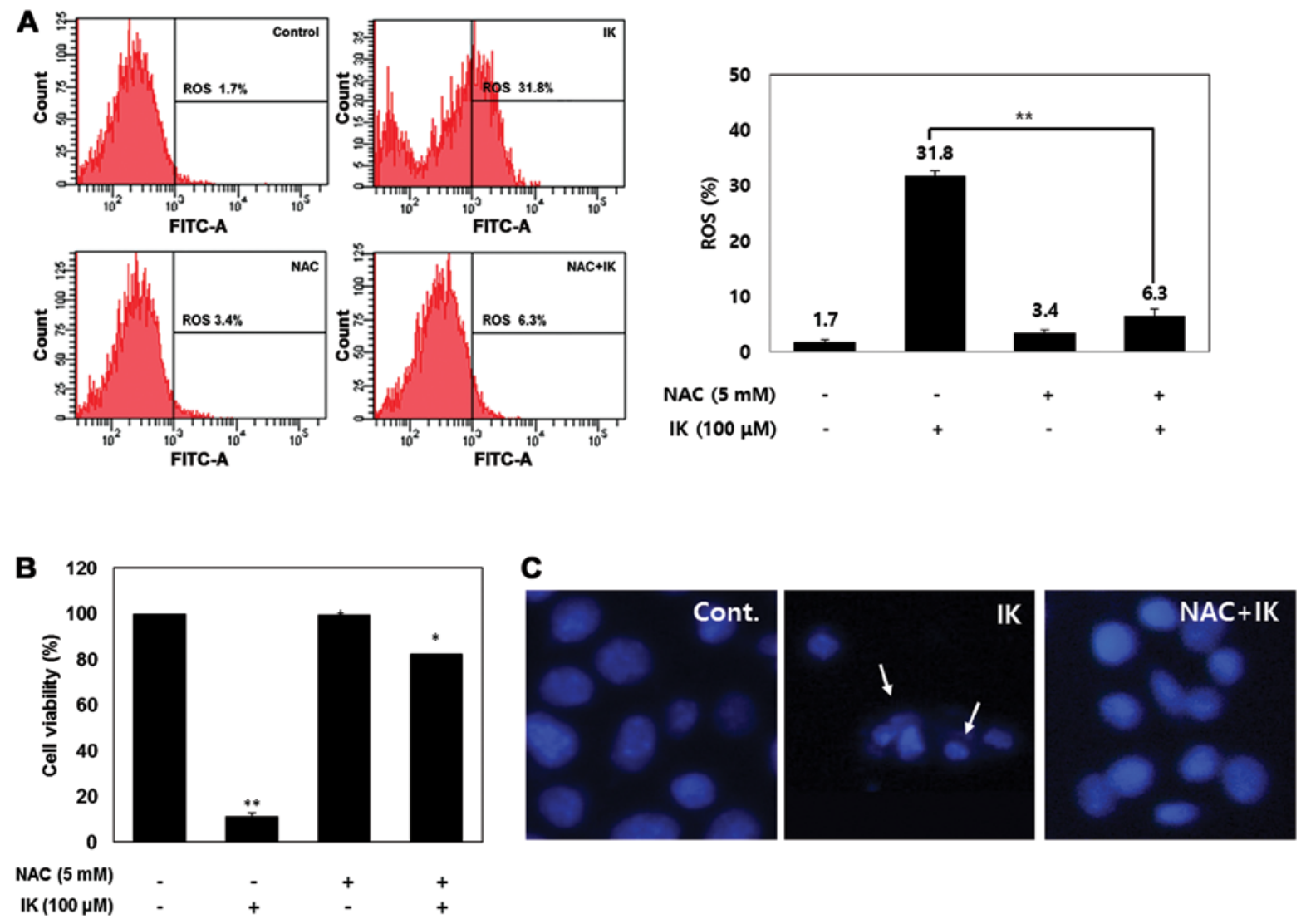

Figure 4. The role of NAC in IK-induced apoptosis. Cells were treated with or without NAC (5 mM) for $2 \mathrm{~h}$ before challenge with $100 \mu \mathrm{M} \mathrm{IK}$ for $24 \mathrm{~h}$. (A) ROS production was measured by flow cytometry. Significant differences were compared with the control at ${ }^{* *} \mathrm{P}<0.01$ using Student's t-test. (B) Cell viability was measured by SRB assay. Significant differences were compared with the control at ${ }^{*} \mathrm{P}<0.05$ and ${ }^{* *} \mathrm{P}<0.01$ using Student's t-test. (C) Nuclear fragmentation was observed by Hoechst staining. 

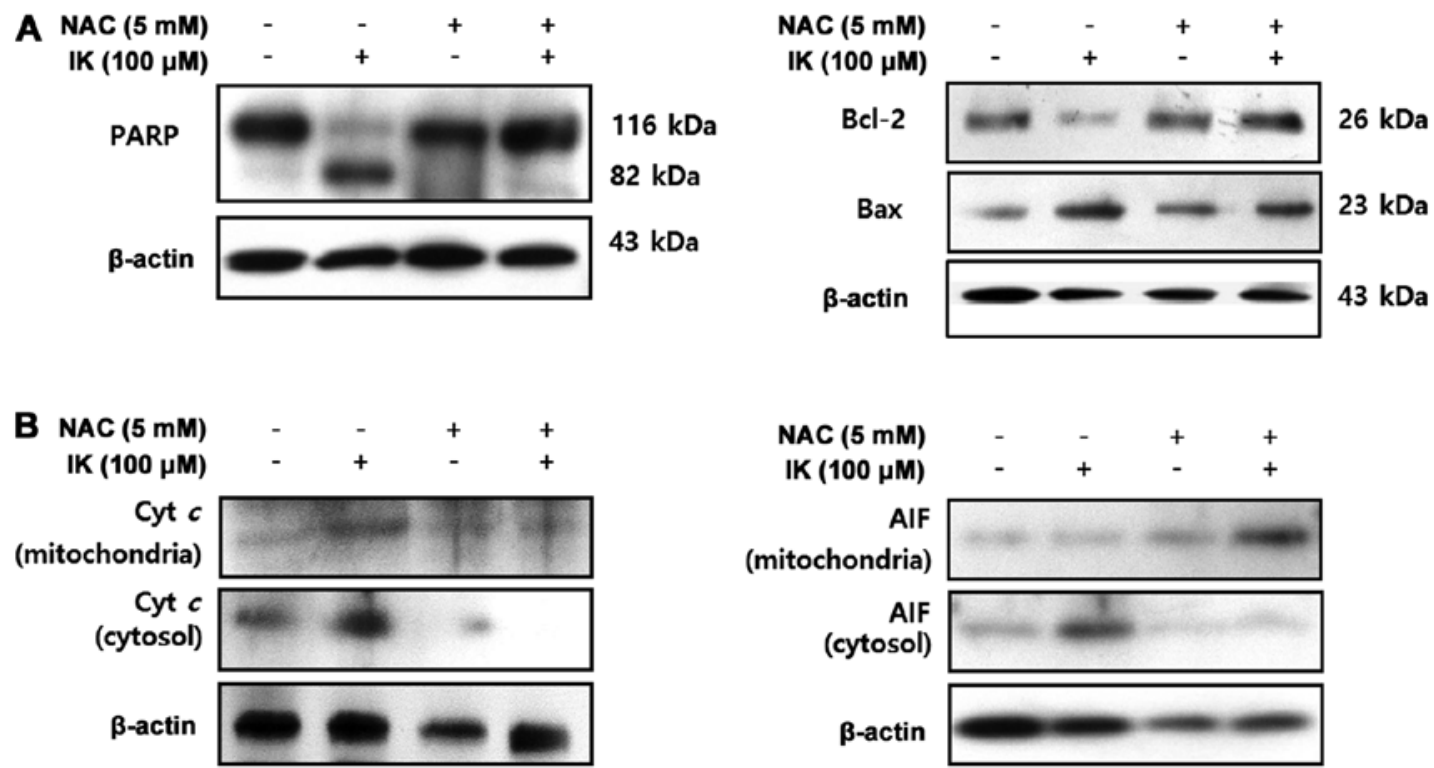

Figure 5. ROS generation and effects of NAC on modulation of cytochrome $c$ and AIF proteins in SK-MEL-2 melanoma cells treated with IK. Cells were treated with or without NAC $(5 \mathrm{mM})$ for $2 \mathrm{~h}$ before challenge with $100 \mu \mathrm{M} \mathrm{IK}$ for $24 \mathrm{~h}$. Cellular proteins were then lysed, separated by SDS-polyacrylamide electrophoresis and transferred onto nitrocellulose membranes. Membranes were probed with the indicated antibodies. Proteins were visualized using an ECL detection system. (A) Expression of PARP, Bcl-2 and Bax in cells treated with IK for $24 \mathrm{~h}$. (B) Release of cytochrome $c$ and AIF.

A

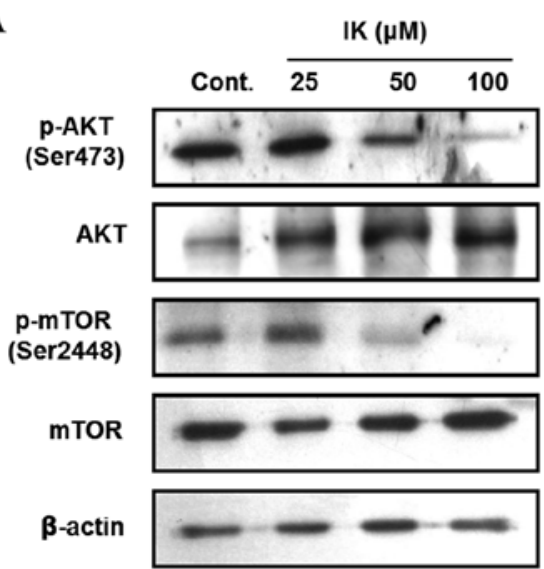

B

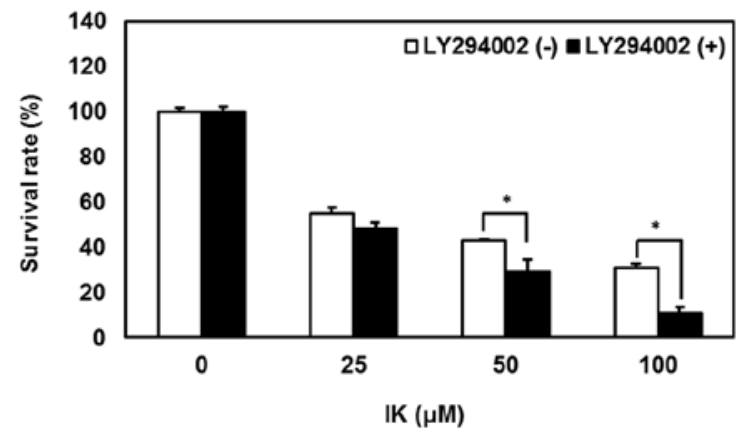

Figure 6. IK inhibits the PI3K/AKT/mTOR signaling pathway. (A) Protein levels of p-AKT, AKT, p-mTOR, mTOR, and $\beta$-actin were analyzed by western blotting using specific antibodies following treatment with 0-100 $\mu \mathrm{M}$ IK for $24 \mathrm{~h}$ in SK-MEL-2 cells. (B) SK-MEL-2 cells were pretreated for $1 \mathrm{~h}$ with $10 \mu \mathrm{M}$ LY294002, a PI3K/AKT inhibitor, followed by IK for $24 \mathrm{~h}$. Cell viability was measured by SRB assay. Data shown are the mean \pm SD of three samples. Data containing asterisk marks are significantly different from the values in non-LY294002 treated cells at ${ }^{*} \mathrm{P}<0.05$ and ${ }^{* *} \mathrm{P}<0.01$.

generation, which induced apoptosis in SK-MEL-2 cells via caspase-dependent and -independent pathways.

Isoegomaketone inhibits growth of melanoma cells via suppression of the PI3K/AKT signaling pathway. The PI3K/ AKT signaling pathway acts as a survival signal by reducing apoptosis and promoting proliferation of various cancer cells $(35,36)$. Therefore, we investigated whether or not IK treatment suppresses the PI3K/AKT signaling pathway in SK-MEL-2 cells. IK-treated cells showed reduced phosphorylation of AKT and mTOR in a dose-dependent manner (Fig. 6A). Furthermore, SK-MEL-2 cells pretreated with LY294002 (PI3K inhibitor) followed by treatment with $100 \mu \mathrm{M}$ IK displayed $20 \%$ greater growth inhibition compared to non-inhibitor treated cells
(Fig. 6B). These results indicate that IK inhibited SK-MEL-2 cell growth by suppressing the PI3K/AKT signaling pathway.

\section{Discussion}

Several reports have shown that Perilla frutescens and its bioactive compounds inhibit cell growth via induction of apoptosis in various cancer cells $(37,38)$. However, there is no published study showing that IK induces apoptotic cell death in SK-MEL-2 human melanoma cells via ROS-dependent activation of a mitochondrial pathway and inhibition of PI3K/ AKT signaling. In the present study, we showed that IK significantly induced cell morphological changes and reduced cell viability in SK-MEL-2 cells. Furthermore, the results of 
cell cycle analysis and Hoechst 33258 staining demonstrated that IK treatment increased sub-G1 contents, nuclei condensation, formation of apoptotic bodies, and DNA fragmentation in a dose-dependent manner. The current results suggest that IK treatment induces cell death in SK-MEL-2 cells through activation of apoptotic signaling pathways.

Caspases, which are a family of cysteine-dependent aspartate-directed proteases, play critical roles in the initiation and execution of apoptosis (39). One of the major pathway for the activation of caspase-dependent apoptosis is receptormediated caspase- 8 while another is cytochrome $c$-mediated caspase- 9 activation. The pathway is regulated by $\mathrm{Bcl}-2$ family proteins, and their end result is caspase-3 activation $(40,41)$. Ectopic (extra-mitochondrial) AIF causes chromatin condensation and DNA fragmentation, and these reactions are induced by caspase-activated DNase or Acinus $(34,41,42)$. Therefore, AIF might play an important role in caspase-independent apoptotic death. In this study, IK activated caspase-3 and -9, upregulated Bax expression, downregulated Bcl-2 expression, and induced cleavage of PARP. This result indicates that IK treatment not only induced caspase-dependent apoptotic death but also induced apoptosis in association with a caspase-independent pathway. These findings are supported by previous studies that IK induces apoptosis in DLD1 cells by regulation of caspase-dependent pathway (7).

Previous studies have shown that reactive oxygen species (ROS) effectively induce apoptosis in various cancer cell lines $(43,44)$. Furthermore, many studies showed that ROS-mediated apoptosis is induced by natural compounds. Oridonin treatment along with NAC has been shown to inhibit ROS generation in HepG2 cells as well as reduce apoptotic cell death (45). Further, treatment with NAC prevents curcumin-induced cell apoptosis in human lung adenocarcinoma A549 cells (46). Our results show that IK treatment along with NAC inhibited cell death and prevented apoptotic cell death in SK-MEL-2 cells. Moreover, we demonstrated that NAC treatment inhibited upregulation of Bax expression and downregulation of Bcl-2 expression in IK-treated SK-MEL-2 cells. In addition, ROS production in SK-MEL-2 cells induced the release cytochrome $c$ from mitochondria into the cytosol. The release of cytochrome $c$ triggers apoptotic protease-activating factor-1 (Apaf-1)-mediated activation of caspase-9, which in turn stimulates other caspase events such as caspase-3 activation (47). We also observed that ROS generation induced AIF translocation from mitochondria into the nucleus in SK-MEL-2 cells. These results suggest that IK-induced apoptotic cell death in SK-MEL-2 cells involved caspase-dependent and -independent pathways triggered by IK-mediated ROS generation.

The PI3K/AKT signaling pathway plays a critical role in cell proliferation, survival, and metastasis in numerous cancer cell lines $(48,49)$, including melanoma (49). Therefore, current cancer therapeutic studies have mainly focused on regulation of the PI3K/AKT signaling pathway $(50,51)$. In this study, IK treatment inhibited the phosphorylation of AKT and mTOR. Specifically, we pretreated SK-MEL-2 cells with LY294002 (PI3K inhibitor) to confirm whether or not IK inhibits SK-MEL-2 cell growth via regulation of the PI3K/AKT signaling pathway. The results suggest that IK can be used as an AKT regulation factor for the treatment of melanoma.
In conclusion, this study is the first to confirm that IK inhibits cell growth in SK-MEL-2 human melanoma cells by triggering ROS-mediated caspase-dependent and -independent apoptotic cell death and suppression of the PI3K/AKT signaling pathway. These findings suggest that IK can be used as a fundamental resource for the development of new agents for melanoma treatment.

\section{References}

1. Park K, Nam D, Yun H, et al: B-caryophyllene oxide inhibits growth and induces apoptosis through the suppression of $\mathrm{PI} 3 \mathrm{~K} / \mathrm{AKT} / \mathrm{mTOR} / \mathrm{S} 6 \mathrm{~K} 1$ pathways and ROS-mediated MAPKs activation. Cancer Lett 312: 178-188, 2011.

2. Seo WH and Baek HH: Characteristic aroma-active compounds of korean perilla (perilla frutescens britton) leaf. J Agric Food Chem 57: 11537-11542, 2009.

3. Choung M, Kwon Y and Kwak Y: Test of components related to quality in perilla leaves: II. test of volatile flavor components in perilla leaves. RDA J Agric Sci 40: 127-132, 1998.

4. Lee B: Comparison of analytical methods for volatile flavor compounds in leaf of perilla frutescens. Korean J Crop Sci 44: 154-158, 1999.

5. Lim S, Seo Y, Lee Y and Baek N: Isolation of volatile allelochemicals from leaves of perilla frutescens and artemisia asiatica. Agricult Chem Biotechnol 37: 115-123, 1994.

6. Park YD, Jin CH, Choi DS, Byun M and Jeong IY: Biological evaluation of isoegomaketone isolated from perilla frutescens and its synthetic derivatives as anti-inflammatory agents. Arch Pharm Res 34: 1277-1282, 2011.

7. Cho BO, Jin CH, Park YD, Ryu HW, Byun MW, Seo KI and Jeong IY: Isoegomaketone induces apoptosis through caspase-dependent and caspase-independent pathways in human DLD1 cells. Biosci Biotechnol Biochem 75: 1306-1311, 2011.

8. Devasagayam TP, Tilak JC, Boloor KK, Sane KS, Ghaskadbi SS and Lele RD: Free radicals and antioxidants in human health: current status and future prospects. J Assoc Physicians India 52: 794-804, 2004.

9. Simon H, Haj-Yehia A and Levi-Schaffer F: Role of reactive oxygen species (ROS) in apoptosis induction. Apoptosis 5: 415-418, 2000.

10. Sander C, Hamm F, Elsner P and Thiele J: Oxidative stress in malignant melanoma and non-melanoma skin cancer. Br J Dermatol 148: 913-922, 2003.

11. Ralph SJ, Rodríguez-Enríquez S, Neuzil J and MorenoSánchez R: Bioenergetic pathways in tumor mitochondria as targets for cancer therapy and the importance of the ROS-induced apoptotic trigger. Mol Aspects Med 31: 29-59, 2010.

12. Raj L, Ide T, Gurkar AU, et al: Selective killing of cancer cells by a small molecule targeting the stress response to ROS. Nature 475: 231-234, 2011.

13. Trachootham D, Alexandre J and Huang P: Targeting cancer cells by ROS-mediated mechanisms: a radical therapeutic approach? Nat Rev Drug Discov 8: 579-591, 2009.

14. Morgensztern D and McLeod HL: PI3K/akt/mTOR pathway as a target for cancer therapy. Anticancer Drugs 16: 797-803, 2005.

15. Yap TA, Garrett MD, Walton MI, Raynaud F, de Bono JS and Workman P: Targeting the PI3K-AKT-mTOR pathway: progress, pitfalls, and promises. Curr Opin Pharmacol 8: 393-412, 2008.

16. Baselga J, Campone M, Piccart M, et al: Everolimus in postmenopausal hormone-receptor-positive advanced breast cancer. N Engl J Med 366: 520-529, 2012.

17. Vara JÁF, Casado E, de Castro J, Cejas P, Belda-Iniesta C and González-Barón M: PI3K/akt signalling pathway and cancer. Cancer Treat Rev 30: 193-204, 2004.

18. Brugge J, Hung M and Mills GB: A new mutational aktivation in the PI3K pathway. Cancer Cell 12: 104-107, 2007.

19. Agarwal R, Carey M, Hennessy B and Mills GB: PI3K pathwaydirected therapeutic strategies in cancer. Curr Opin Investig Drugs 11: 615-628, 2010.

20. Lee Y, Jeong H, Kim Y, et al: Reactive oxygen species and PI3K/akt signaling play key roles in the induction of Nrf2-driven heme oxygenase-1 expression in sulforaphane-treated human mesothelioma MSTO-211H cells. Food Chem Toxicol 50: 116-123, 2012. 
21. Liu C, Gong K, Mao X and Li W: Tetrandrine induces apoptosis by activating reactive oxygen species and repressing akt activity in human hepatocellular carcinoma. Int J Cancer 129: 1519-1531, 2011.

22. Mao X, Yu CR, Li WH and Li WX: Induction of apoptosis by shikonin through a ROS/JNK-mediated process in bcr/ablpositive chronic myelogenous leukemia (CML) cells. Cell Res 18: 879-888, 2008.

23. Ka H, Park H, Jung H, Choi J, Cho K, Ha J and Lee $\mathrm{K}$ : Cinnamaldehyde induces apoptosis by ROS-mediated mitochondrial permeability transition in human promyelocytic leukemia HL-60 cells. Cancer Lett 196: 143-152, 2003.

24. Jin CH, Lee HJ, Park YD, et al: Isoegomaketone inhibits lipopolysaccharide-induced nitric oxide production in RAW 264.7 macrophages through the heme oxygenase-1 induction and inhibition of the interferon-beta-STAT-1 pathway. J Agric Food Chem 58: 860-867, 2010.

25. Skehan P, Storeng R, Scudiero D, et al: New colorimetric cytotoxicity assay for anticancer-drug screening. J Natl Cancer Inst 82: $1107-1112,1990$.

26. Park SY, Cho SJ, Kwon HC, Lee KR, Rhee DK and Pyo S: Caspase-independent cell death by allicin in human epithelial carcinoma cells: involvement of PKA. Cancer Lett 224: 123-132, 2005.

27. Ricote M, Garcia-Tunon I, Fraile B, Fernandez C, Aller P Paniagua R and Royuela M: P38 MAPK protects against TNF-alpha-provoked apoptosis in LNCaP prostatic cancer cells. Apoptosis 11: 1969-1975, 2006.

28. Kim JY, Park KW, Moon KD, et al: Induction of apoptosis in HT-29 colon cancer cells by crude saponin from platycodi radix. Food Chem Toxicol 46: 3753-3758, 2008

29. Kuo PL, Hsu YL, Chang CH and Lin CC: The mechanism of ellipticine-induced apoptosis and cell cycle arrest in human breast MCF-7 cancer cells. Cancer Lett 223: 293-301, 2005.

30. Chen CY, Liu TZ, Liu YW, et al: 6-shogaol (alkanone from ginger) induces apoptotic cell death of human hepatoma p53 mutant mahlavu subline via an oxidative stress-mediated caspase-dependent mechanism. J Agric Food Chem 55: 948-954, 2007.

31. Wan CK, Wang C, Cheung HY, Yang M and Fong WF: Triptolide induces bcl-2 cleavage and mitochondria dependent apoptosis in p53-deficient HL-60 cells. Cancer Lett 241: 31-41, 2006.

32. Alnemri ES, Livingston DJ, Nicholson DW, Salvesen G, Thornberry NA, Wong WW and Yuan J: Human ICE/CED-3 protease nomenclature. Cell 87: 171, 1996.

33. Tsujimoto Y: Role of bcl-2 family proteins in apoptosis: apoptosomes or mitochondria? Genes Cells 3: 697-707, 1998.

34. Candé C, Cecconi F, Dessen P and Kroemer G: Apoptosisinducing factor (AIF): key to the conserved caspase-independent pathways of cell death? J Cell Sci 115: 4727-4734, 2002.

35. Alvarez M, Roman E, Santos ES and Raez LE: New targets for non-small-cell lung cancer therapy. Expert Rev Anticancer Ther 7: 1423-1437, 2007.

36. Di Cosimo S, Scaltriti M, Val D, et al: The PI3-K/AKT/mTOR pathway as a target for breast cancer therapy. J Clin Oncol 25 (Suppl 18): 3511, 2007.
37. Lin C, Kuo C, Wang J, Cheng J, Huang Z and Chen C: Growth inhibitory and apoptosis inducing effect of Perilla frutescens extract on human hepatoma HepG2 cells. J Ethnopharmacol 112: 557-567, 2007.

38. Osakabe N, Yasuda A, Natsume M and Yoshikawa T: Rosmarinic acid inhibits epidermal inflammatory responses: anticarcinogenic effect of perilla frutescens extract in the murine two-stage skin model. Carcinogenesis 25: 549-557, 2004.

39. Budihardjo I, Oliver H,Lutter M, Luo X and Wang X: Biochemical pathways of caspase activation during apoptosis. Annu Rev Cell Dev Biol 15: 269-290, 1999.

40. Earnshaw WC, Martins LM and Kaufmann SH: Mammalian caspases: structure, activation, substrates, and functions during apoptosis. Annu Rev Biochem 68: 383-424, 1999.

41. Köhler C, Orrenius S and Zhivotovsky B: Evaluation of caspase activity in apoptotic cells. J Immunol Methods 265: 97-110, 2002.

42. Susin SA, Lorenzo HK, Zamzami N, et al: Molecular characterization of mitochondrial apoptosis-inducing factor. Nature 397: 441-446, 1999.

43. Su C, Lin J, Li T, et al: Curcumin-induced apoptosis of human colon cancer colo 205 cells through the production of ROS, Ca2 and the activation of caspase-3. Anticancer Res 26: 4379-4389, 2006.

44. Hwang J, Ha J, Park I, Lee S, Baik HW, Kim YM and Park OJ: Apoptotic effect of EGCG in HT-29 colon cancer cells via AMPK signal pathway. Cancer Lett 247: 115-121, 2007.

45. Huang J, Wu L, Tashiro S, Onodera S and Ikejima T: Reactive oxygen species mediate oridonin-induced HepG2 apoptosis through p53, MAPK, and mitochondrial signaling pathways. J Pharmacol Sci 107: 370-379, 2008.

46. Chen Q, Wang Y, Xu K, et al: Curcumin induces apoptosis in human lung adenocarcinoma A549 cells through a reactive oxygen species-dependent mitochondrial signaling pathway. Oncol Rep 23: 397-403, 2010.

47. Slee EA, Harte MT, Kluck RM, et al: Ordering the cytochrome $c$-initiated caspase cascade: hierarchical activation of caspases-2,-3,-6,-7,-8, and-10 in a caspase-9-dependent manner. J Cell Biol 144: 281-292, 1999.

48. Brunet A, Datta SR and Greenberg ME: Transcription-dependent and-independent control of neuronal survival by the PI3K-Akt signaling pathway. Curr Opin Neurobiol 11: 297-305, 2001.

49. Madhunapantula SV, Mosca PJ and Robertson GP: The akt signaling pathway: an emerging therapeutic target in malignant melanoma. Cancer Biol Ther 12: 1032-1049, 2011.

50. Chang F, Lee J, Navolanic P, et al: Involvement of PI3K/akt pathway in cell cycle progression, apoptosis, and neoplastic transformation: a target for cancer chemotherapy. Leukemia 17: 590-603, 2003

51. Osaki M, Oshimura Ma and Ito H: PI3K-akt pathway: its functions and alterations in human cancer. Apoptosis 9: 667-676, 2004. 